\title{
Boosting the Metathesis Activity of Molybdenum Oxo Alkylidenes by Tuning the Anionic Ligand $\sigma$ Donation
}

\section{Journal Article}

\section{Author(s):}

De Jesus Silva, Jordan (D); Pucino, Margherita; Zhai, Feng; Mance, Deni; Berkson, Zachariah J.; Nater, Darryl F.; Hoveyda, Amir H.; Copéret, Christophe (iD; Schrock, Richard R.

\section{Publication date:}

2021-05-17

\section{Permanent link:}

https://doi.org/10.3929/ethz-b-000489077

\section{Rights / license:}

In Copyright - Non-Commercial Use Permitted

\section{Originally published in:}

Inorganic Chemistry 60(10), https://doi.org/10.1021/acs.inorgchem.0c03173

\section{Funding acknowledgement:}

190322 - Predictive design in heterogeneous catalysis through machine learning and surface organometallic chemistry (SNF) 192050 - Molecular Approach and Understanding in Heterogeneous Catalysis (SNF)

169134 - Molecular Approach to Heterogeneous Catalysis (SNF) 


\title{
Boosting the Metathesis Activity of Molybdenum Oxo Alkylidenes by Tuning the Anionic Ligand $\sigma$ Donation
}

\author{
Jordan De Jesus Silva, ${ }^{\dagger}$ Margherita Pucino, ${ }^{\dagger}$ Feng Zhai, Deni Mance, Zachariah J. Berkson, \\ Darryl F. Nater, Amir H. Hoveyda, Christophe Copéret,* and Richard R. Schrock*
}

Cite This: https://dx.doi.org/10.1021/acs.inorgchem.0c03173

Q Read Online

ACCESS | Џ Metrics \& More | 回 Article Recommendations

| S1 Supporting Information

ABSTRACT: The catalytic performances of molecular and silicasupported molybdenum oxo alkylidene species bearing anionic $\mathrm{O}$ ligands $\left[\mathrm{OR}_{\mathrm{F} 9}, \mathrm{OTPP}, \mathrm{OHMT}-\right.$ where $\mathrm{OR}_{\mathrm{F} 9}=\mathrm{OC}\left(\mathrm{CF}_{3}\right)_{3}, \mathrm{OTPP}$ $=$ 2,3,5,6-tetraphenylphenoxy, OHMT = hexamethylterphenoxy] with different $\sigma$-donation abilities and sizes are evaluated in the metathesis of both internal and terminal olefins. Here, we show that the presence of the anionic nonafluoro-tert-butoxy $\mathrm{X}$ ligand in $\mathrm{Mo}(\mathrm{O})\left\{=\mathrm{CH}-4-(\mathrm{MeO}) \mathrm{C}_{6} \mathrm{H}_{4}\right\}(\mathrm{THF})_{2}\{\mathrm{X}\}_{2} \quad\left(\mathbf{1} ; \mathrm{X}=\mathrm{OR}_{\mathrm{F} 9}\right)$ significantly increases the catalytic performances in the metathesis of both terminal and internal olefins. Its silica-supported equivalent displays slightly lower activity, albeit with improved stability. In

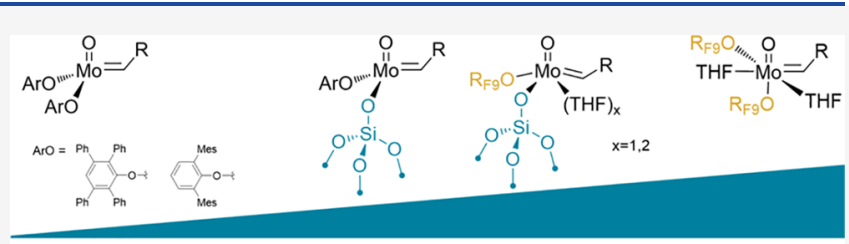

Activity in internal and terminal olefin metathesis

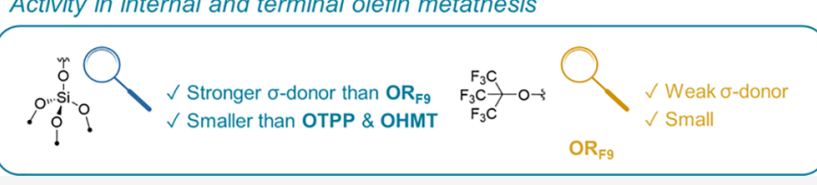
sharp contrast, the molecular complexes with large aryloxy anionic $\mathrm{X}$ ligands show little activity, whereas the activity of the corresponding silica-supported systems is greatly improved, illustrating that surface siloxy groups are significantly smaller anionic ligands. Of all of the systems, compound 1 stands out because of its unique high activity for both terminal and internal olefins. Density functional theory modeling indicates that the $\mathrm{OR}_{\mathrm{F} 9}$ ligand is ideal in this series because of its weak $\sigma$-donating ability, avoiding overstabilization of the metallacyclobutane intermediates while keeping low barriers for $[2+2]$ cycloaddition and turnstile isomerization.

\section{INTRODUCTION}

Olefin metathesis has become a key reaction for the synthesis of basic chemicals as well as complex molecular architectures including polymers, growing in importance in both academia and industry. ${ }^{1}$ Since its early mechanistic proposal, ${ }^{2}$ continuous efforts have been directed at gaining a detailed understanding of what makes specific metal alkylidenes good for this catalytic reaction. ${ }^{3}$ For instance, for early-transitionmetal $\left(\mathrm{d}^{0}\right)$ metathesis catalysts that share a common structural motif- $(\mathrm{X})(\mathrm{Y}) \mathrm{M}(=\mathrm{CHR}) \mathrm{E}^{4}(\mathrm{M}=\mathrm{Mo}$ or $\mathrm{W}, \mathrm{E}=$ imido or oxo ligand, and $\mathrm{X}$ and $\mathrm{Y}$ are anionic ligands) - each ligand has a tremendous influence on the stability of the reaction intermediates and the overall catalytic activity. ${ }^{3 a, 5}$ In that context, surface organometallic chemistry, ${ }^{1 \mathrm{e}, 6}$ in combination with computational chemistry, has played a key role in the identification and understanding of the effect of each ligand. ${ }^{7}$ In particular, these studies, complemented by molecular chemistry, have shown that (i) the trigonal-bipyramidal (TBP) isomer is a key intermediate in the metathesis pathway while the square-pyramidal (SP) isomer is usually more stable and corresponds to an off-cycle intermediate and (ii) the anionic ligands play a major role in the stability of the TBP and SP metallacyclobutane intermediates and, in turn, drive the overall catalytic performance (Scheme $1 \mathrm{~A}){ }^{8}$ In that context, $\mathrm{W}$-based metathesis catalysts display typically poorer activity toward terminal olefin compared to their Mo analogues, because of the significantly higher stability of the parent metallacyclobutane formed from the ethylene byproduct. Nonetheless, their performance, whether molecular or supported, can in most cases be significantly improved by introducing strong $\sigma$-donating ligands like oxo, ${ }^{9}$ thiolate, ${ }^{10}$ or $\mathrm{N}$-heterocyclic carbene (NHC). ${ }^{11}$ Even with molybdenum alkylidenes, which are particularly efficient metathesis catalysts for terminal olefins, their activity can also be dramatically improved by replacing an imido with an oxo ligand (Schemes $1 \mathrm{~B}$ and 2) or by introducing a NHC ligand in their cationic form.

With the recent development of synthetic routes for several molybdenum oxo $p$-methoxybenzylidene complexes $\mathrm{Mo}(\mathrm{O})$ $\left\{=\mathrm{CH}-4-(\mathrm{MeO}) \mathrm{C}_{6} \mathrm{H}_{4}\right\}(\mathrm{THF})_{2}\left(\mathrm{OR}_{\mathrm{F} 9}\right)_{2} \quad\left[\mathbf{1} ; \mathrm{OR}_{\mathrm{F} 9}=\mathrm{OC}-\right.$ $\left.\left(\mathrm{CF}_{3}\right)_{3}\right]$ and $\mathrm{Mo}(\mathrm{O})\left\{=\mathrm{CH}-4-(\mathrm{MeO}) \mathrm{C}_{6} \mathrm{H}_{4}\right\}(\mathrm{OTPP})_{2} \quad$ (2; $\mathrm{OTPP}=2,3,5,6$-tetraphenylphenoxy) (Scheme 1), ${ }^{12}$ we investigate here the role of the $\mathrm{X}$ anionic ligand in metathesis

Special Issue: Heterogeneous Interfaces through the

Lens of Inorganic Chemistry

Received: October 27, 2020 
Scheme 1. (A) Proposed Olefin Metathesis Mechanism for $\mathrm{d}^{0}$ Transition-Metal Catalysts and (B) General Structures of (a) Molybdenum and Tungsten Imido Alkylidene Catalysts, (b) Tungsten Oxo Alkylidene with a Thiolate Ancillary Ligand, and (c) Tungsten Oxo and Molybdenum Imido Alkylidenes with Strong $\sigma$-Donor NHC Ligands

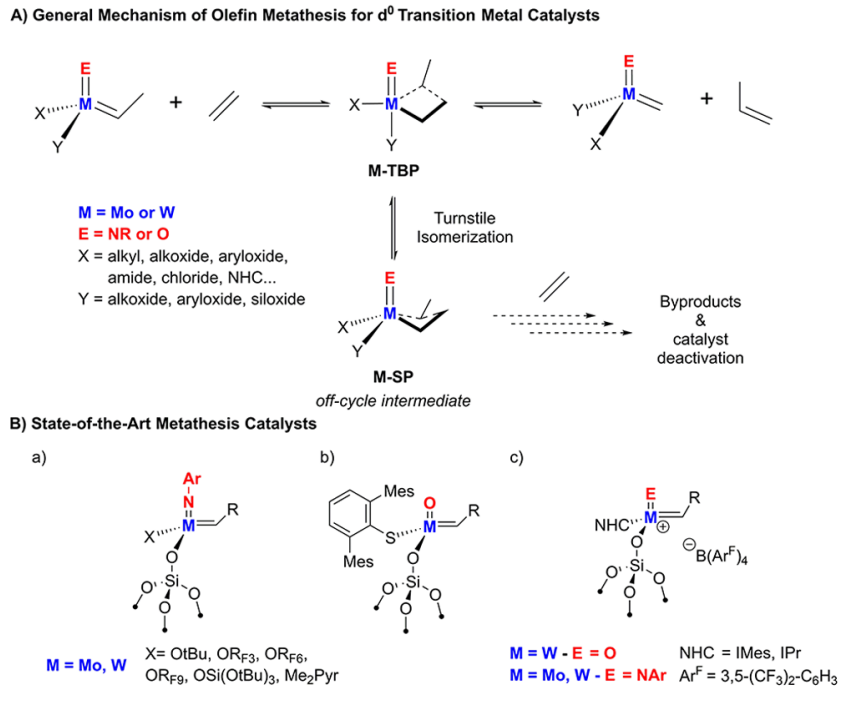

Scheme 2. Grafting Procedures of 1-3, Leading to $1 @ \mathrm{SiO}_{2}$, $2 @ \mathrm{SiO}_{2}$, and 3@SiO 2

This work
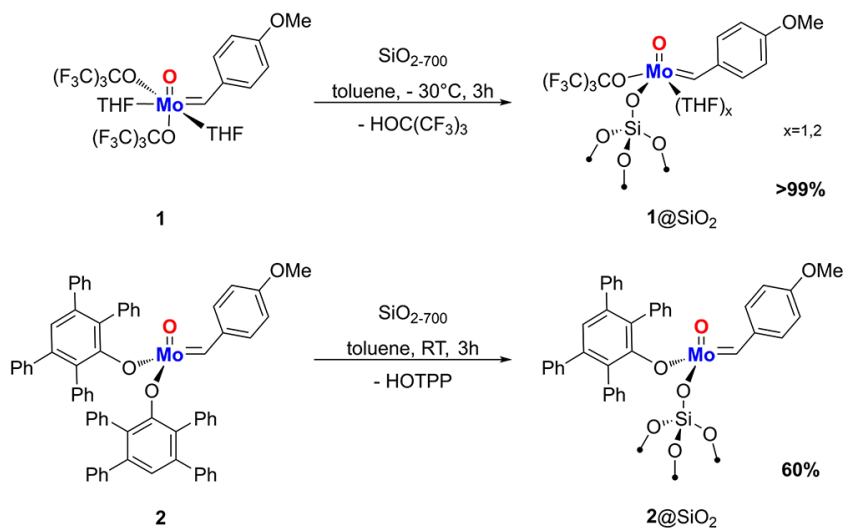

Previously reported (2019)
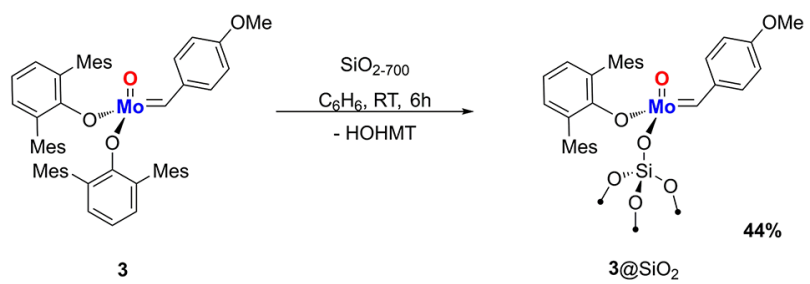

for molecular and silica-supported neutral molybdenum oxo alkylidene complexes. We show that introducing a poor $\sigma$ donating and less sterically demanding ligand, namely, $\mathrm{OR}_{\mathrm{F} 9}$, boosts the activity for the metathesis of both terminal and internal olefins, surpassing previously reported systems.

\section{RESULTS AND DISCUSSION}

Synthesis and Characterization of Silica-Supported Catalysts. First, the silica-supported catalysts 1@SiO $\mathrm{Sin}_{2}$ and $@$
$\mathrm{SiO}_{2}$ were prepared under an inert atmosphere by grafting onto silica partially dehydroxylated at $700{ }^{\circ} \mathrm{C}\left(\mathrm{SiO}_{2-700}\right) \mathbf{1}$ and 2 with $\mathrm{OR}_{\mathrm{F} 9}$ and OTPP anionic ligands, respectively (Scheme 2).

Quantification by elemental analysis showed a Mo loading of 0.24 and $0.17 \mathrm{mmol}$ of $\mathrm{Mo} / \mathrm{g}$ for $1 @ \mathrm{SiO}_{2}$ and $2 @ \mathrm{SiO}_{2}$, respectively, in agreement with solution NMR quantification of the released alcohol/phenol after reaction with silica. In both cases, IR spectroscopy shows that after grafting a large amount of isolated silanols associated with the band at $3747 \mathrm{~cm}^{-1}$ are consumed, in accordance with surface anchoring via protonolysis (Figures $\mathrm{S} 11$ and $\mathrm{S} 14)$. For $2 @ \mathrm{SiO}_{2}$, a broad absorption band around $3500 \mathrm{~cm}^{-1}$ can be observed, corresponding to interaction of the bulky phenoxy ligand with residual $\mathrm{OH}$ groups that are no longer accessible for grafting. ${ }^{13}$ For $1 @ \mathrm{SiO}_{2}$, this band is less prominent, in line with the smaller footprint of complex 1 , hence the observed difference of metal loadings in the respective cases. Furthermore, the band at $2842 \mathrm{~cm}^{-1}$ indicates the presence of at least one coordinated tetrahydrofuran (THF). ${ }^{1} \mathrm{H}$ magicangle-spinning (MAS) NMR spectra of the silica-supported complexes show the alkylidene proton resonances at 14 and 13 ppm for 1@SiO 2 and $2 @ \mathrm{SiO}_{2}$, respectively, slightly downfield with respect to the molecular precursor signals in solution (13.7 and $11.8 \mathrm{ppm}$; Figures S8 and S12). The signal at 7.4 ppm can be assigned to protons of the phenyl moieties, and the resonances at 2.6, 1.9, and 1.4 ppm for $2 @ \mathrm{SiO}_{2}$ can be attributed to the interaction of organometallic fragments with adjacent $\mathrm{OH}$ groups. ${ }^{13}$ Similar signals can be seen for $1 @ \mathrm{SiO}_{2}$ at 2.9 and $1.9 \mathrm{ppm}$. The ${ }^{13} \mathrm{C}$ cross-polarization (CP) MAS NMR spectrum of $1 @ \mathrm{SiO}_{2}$ shows the presence of aromatics, the methoxy at $54 \mathrm{ppm}$ as well as resonances at 25 and $75 \mathrm{ppm}$ associated with coordinated THF (Figure S9). Because the solid-state ${ }^{13} \mathrm{C}$ NMR spectrum did not show any signals from the natural abundance, the ${ }^{13} \mathrm{C}$-enriched supported species of the metathetically more active catalyst $1 @ \mathrm{SiO}_{2}, 1 * @ \mathrm{SiO}_{2}$, was prepared through metathesis of $\mathbf{1}$ with ${ }^{13} \mathrm{C}$-labeled 4-vinylanisole followed by grafting on silica. As shown by ${ }^{1} \mathrm{H}$ and ${ }^{13} \mathrm{C}$ NMR (Figures S6 and S7), the labeled complex $1^{*}$ is obtained as a mixture of syn and anti isomers and corresponds to the mono-THF adduct, as confirmed by X-ray crystallography (see the Supporting Information for more details). Subsequent grafting of $1^{*}$ on $\mathrm{SiO}_{2-700}$ was performed. The ${ }^{13} \mathrm{C}$ CP MAS spectrum of 1*@SiO 2 shows the same signals as those detected in $1 @ \mathrm{SiO}_{2}$ with an additional ${ }^{13} \mathrm{C}$ resonance at $293 \mathrm{ppm}$ from the labeled alkylidene carbon, which exhibits several prominent spinning sidebands consistent with a large chemical shift anisotropy that is typical of molybdenum alkylidenes (Figure S16). ${ }^{14}$ Solid-state ${ }^{19} \mathrm{~F}$ NMR was also measured for $1 @ \mathrm{SiO}_{2}$, showing a single peak at $-76.5 \mathrm{ppm}$ associated with the pendant $\mathrm{OR}_{\mathrm{F} 9}$ ligand (Figure $\mathrm{S} 10$ ).

Catalytic Testing. The metathesis activity of both molecular and supported complexes was evaluated in a nitrogen filled glovebox using cis-4-nonene and 1-nonene as prototypical substrates. The data, including these for $\mathrm{Mo}(\mathrm{O})$ $\left\{=\mathrm{CH}-4-(\mathrm{MeO}) \mathrm{C}_{6} \mathrm{H}_{4}\right\}(\mathrm{OHMT})_{2}$ (3; OHMT = hexamethylterphenoxy) and its supported analogue $3 @ \mathrm{SiO}_{2}$ that were previously reported, ${ }^{15}$ are summarized in Table 1 . Detailed kinetic profiles can be found in the Supporting Information.

For cis-4-nonene, the molecular complex 1 reaches equilibrium conversion within the first $3 \mathrm{~min}$ at $0.02 \mathrm{~mol} \%$ loading with an (under)estimated turnover frequency of 870 $\mathrm{min}^{-1}$. As the catalyst loading is further lowered to $0.014 \mathrm{~mol}$ 
Table 1. Homometathesis of cis-4-Nonene and 1-Nonene (Toluene, $30{ }^{\circ} \mathrm{C}$ )

\begin{tabular}{|c|c|c|c|c|c|}
\hline \multirow[b]{2}{*}{ catalyst } & \multirow[b]{2}{*}{$\operatorname{mol~\% ~}$} & \multicolumn{2}{|c|}{$\mathrm{TOF}_{3 \min }, \min ^{-1}(\text { conversion, } \%)^{a}$} & \multicolumn{2}{|c|}{ time to equilibrium/maximum conversion ${ }^{b}$} \\
\hline & & cis-4-nonene & 1-nonene & cis-4-nonene & 1-nonene \\
\hline 1 & 0.1 & $170(52)^{c}$ & $210(62)$ & $3 \mathrm{~min}$ & $97 \%$ after $4 \mathrm{~h}$ \\
\hline 1 & 0.02 & $870(52)^{c}$ & $940(58)$ & $3 \min$ & $97 \%$ after $4 \mathrm{~h}$ \\
\hline 1 & 0.014 & $250(11)$ & & $11 \%$ after $1 \mathrm{~h}$ & \\
\hline 1 & 0.01 & & $1270(38)$ & & $50 \%$ after $4 \mathrm{~h}$ \\
\hline 2 & 0.1 & $1(<1)$ & $30(9)$ & $4 \%$ after $1 \mathrm{~h}$ & $62 \%$ after $4 \mathrm{~h}$ \\
\hline $3^{d}$ & 0.1 & $5(1)$ & $<1$ & $3 \%$ after $24 \mathrm{~h}$ & $45 \%$ after $8 \mathrm{~h}$ \\
\hline $1 @ \mathrm{SiO}_{2}$ & 0.1 & $170(51)^{c}$ & $70(22)$ & $3 \min$ & $97 \%$ after $4 \mathrm{~h}$ \\
\hline $1 @ \mathrm{SiO}_{2}$ & 0.02 & $725(42-46)^{c, e}$ & $170(10)$ & $5-10 \min ^{e}$ & $73 \%$ after $8 \mathrm{~h}$ \\
\hline $1 @ \mathrm{SiO}_{2}$ & 0.014 & $680(29)$ & & $10 \mathrm{~min}$ & \\
\hline $1 @ \mathrm{SiO}_{2}$ & 0.005 & $100(1)$ & & $41 \%$ after $9 \mathrm{~h}$ & \\
\hline $2 @ \mathrm{SiO}_{2}$ & 0.1 & $170(52)^{c}$ & $40(12)$ & $3 \min$ & $98 \%$ after $6 \mathrm{~h}$ \\
\hline $2 @ \mathrm{SiO}_{2}$ & 0.02 & $350(24)$ & $70(5)$ & $30 \mathrm{~min}$ & $95 \%$ after $8 \mathrm{~h}$ \\
\hline $3 @ \mathrm{SiO}_{2}{ }^{d}$ & 0.1 & $120(40)^{c}$ & $75(13)$ & $10 \mathrm{~min}$ & $98 \%$ after $8 \mathrm{~h}$ \\
\hline $3 @ \mathrm{SiO}_{2}{ }^{d}$ & 0.02 & $300(17)$ & & $1 \mathrm{~h}$ & \\
\hline $3 @ \mathrm{SiO}_{2}{ }^{d}$ & 0.014 & $410(18)$ & $70(4)$ & $1 \mathrm{~h}$ & $97 \%$ after $24 \mathrm{~h}$ \\
\hline $3 @ \mathrm{SiO}_{2}{ }^{d}$ & 0.005 & $520(8)$ & $45(1)$ & $28 \%$ after $24 \mathrm{~h}$ & $63 \%$ after $24 \mathrm{~h}$ \\
\hline
\end{tabular}

${ }^{a} \mathrm{TOF}$ at $3 \mathrm{~min}$, given in $\mathrm{min}^{-1}$, with the corresponding conversions given in parentheses. Equilibrium conversion is $50 \%{ }^{b}$ Maximum conversion is $100 \%$. When full conversion was not reached, the maximum conversion measured after a given time is provided. ${ }^{c}$ The TOF value is underestimated given that the conversion is close to equilibrium. ${ }^{d}$ Previously reported results in ref $15 .{ }^{e}$ Performed in duplicate and averaged.

Table 2. Relative Gibbs Free Energies and Reaction Enthalpies (kcal/mol) of Molecular and Grafted Oxo Alkylidene Complexes with Respect to Separate Reactants (Methylidene and Ethylene)

\begin{tabular}{|c|c|c|c|c|c|}
\hline catalyst & $\mathrm{TOF}_{3 \min }(0.1 \mathrm{~mol} \%)$ for 1 -nonene & $\Delta G_{[2+2]}^{\ddagger}\left(\Delta H_{[2+2]}^{\ddagger}\right)$ & $\Delta G_{\mathrm{TBP}}\left(\Delta H_{\mathrm{TBP}}\right)$ & $\Delta G_{\text {turnstile }}^{\ddagger}\left(\Delta H_{\text {turnstile }}^{\ddagger}\right)$ & $\Delta G_{\mathrm{SP}}\left(\Delta H_{\mathrm{SP}}\right)$ \\
\hline 1 & 210 & $8.12(-6.25)$ & $-2.60(-16.66)$ & $8.38(-6.45)$ & $-8.46(-22.54)$ \\
\hline 2 & 30 & $a$ & $2.06(-11.40)$ & $a$ & $-11.23(-22.67)$ \\
\hline 3 & $<1$ & $a$ & $3.42(-12.81)$ & $a$ & $-6.57(-20.42)$ \\
\hline $\mathbf{1} @ \mathrm{SiO}_{2}$ & 70 & $a$ & $\begin{array}{l}\text { axial siloxy }-0.08(-15.47) \\
\text { equatorial siloxy }-1.96(-16.60)\end{array}$ & $a$ & $-10.39(-24.44)$ \\
\hline $2 @ \mathrm{SiO}_{2}$ & 40 & $a$ & $-1.70(-14.87)$ & $a$ & $-14.36(-26.71)$ \\
\hline $3 @ \mathrm{SiO}_{2}$ & 75 & $a$ & $-0.37(-15.21)$ & $a$ & $-9.74(-24.53)$ \\
\hline
\end{tabular}

${ }^{a}$ Not calculated.

$\%$, the conversion is fast but stagnates at $11 \%$ because of deactivation, as indicated by the substantially lower $\mathrm{TOF}_{3 \mathrm{~min}}$ of $250 \mathrm{~min}^{-1}$. This sharply contrasts with the catalyst performance of the molecular complex 2 , which shows very low activity at $0.1 \mathrm{~mol} \%$ loading, reaching only $4 \%$ conversion after $1 \mathrm{~h}$. This parallels the low activity of the previously reported dimesitylphenoxy analogue 3 , which only reaches $3 \%$ conversion after $24 \mathrm{~h}$ under the same conditions. This lack of reactivity is likely associated with the presence of a large aryloxy ligand that prevents the necessary distortion of the metal complex to a trigonal prism to accommodate the incoming olefin. ${ }^{15}$ In fact, the corresponding silica-supported systems 2@SiO 2 and $3 @ \mathrm{SiO}_{2}$ are far more active, reaching full conversion and high $\mathrm{TOF}_{3 \mathrm{~min}}$ at $0.02 \mathrm{~mol} \%$ (equilibrium conversion after $30 \mathrm{~min}$ and $1 \mathrm{~h}$ and $\mathrm{TOF}_{3 \mathrm{~min}}=350$ and 300 $\min ^{-1}$, respectively). 1@ $\mathrm{SiO}_{2}$ displays unprecedented high activity toward internal olefins for Mo, reaching $\mathrm{TOF}_{3 \text { min }}$ of $725 \mathrm{~min}^{-1}$ at $0.02 \mathrm{~mol} \%$ loading and thereby surpassing even the highest value previously reported for grafted molybdenum oxo complexes at significantly lower loading $\left(\mathrm{TOF}_{3 \text { min }}=520\right.$ $\left.\min ^{-1}, 0.005 \mathrm{~mol} \%\right) .{ }^{15}$ In comparison to the molecular counterpart 1, the stability of $1 @ \mathrm{SiO}_{2}$ is also increased as the catalyst remained active even at 50 ppm loading ( $41 \%$ conversion after $9 \mathrm{~h}$ ).

For 1-nonene, the activity of the molecular complex 1 exceeds the activity toward internal olefins, reaching $\mathrm{TOF}_{3 \text { min }}$ of $1270 \mathrm{~min}^{-1}$ at a low loading of $0.01 \mathrm{~mol} \%$. Here again, deactivation is observed as the conversion stagnates at $50 \%$ after $4 \mathrm{~h}$. Compared to the results of the homometathesis of cis-4-nonene, the molecular complex 2 at $0.1 \mathrm{~mol} \%$ loading is more active toward the terminal olefin with $\mathrm{TOF}_{3 \text { min }}$ of 30 $\min ^{-1}$ but suffers from deactivation as well, as seen by a conversion reaching only $62 \%$ after $4 \mathrm{~h}$. The supported catalysts 1@SiO 2 and $2 @ \mathrm{SiO}_{2}$ are both active at $0.02 \mathrm{~mol} \%$ loading, reaching $\mathrm{TOF}_{3 \mathrm{~min}}$ values of 170 and $80 \mathrm{~min}^{-1}$, respectively.1@ $@ \mathrm{SiO}_{2}$ does not reach full conversion within $8 \mathrm{~h}$ (73\% conversion) because of deactivation. This parallels the results observed for $3 @ \mathrm{SiO}_{2}$, showing an activity similar to that of $1 @ \mathrm{SiO}_{2}$ at high catalyst loadings $(0.1 \mathrm{~mol} \%, 75$ vs 70 $\left.\min ^{-1}\right)$; the catalyst also deactivates at lower loadings $(0.014$ $\left.\mathrm{mol} \%, \mathrm{TOF}_{3 \mathrm{~min}}=70 \mathrm{~min}^{-1}\right)$, reaching equilibrium conversion only after $24 \mathrm{~h}$.

Computational Analysis. Density functional theory calculations (PBE/def2-TZVP//PBE0/def2-TZVP with SDD effective core potential for Mo, ultrafine integration grid, and GD3BJ empirical dispersion) were performed to gain further insight into the origin of the molybdenum oxo alkylidene metathesis catalytic activity. The relative stabilities of TBP and SP unsubstituted metallacycles were assessed for all systems because these key intermediates typically control the turnover rates, in particular for the metathesis of terminal olefins where ethylene is formed. The energies were calculated for both 
molecular and silica-supported molybdenum oxo alkylidenes 1-3 and 1-3@SiO 2 (see Table 2 and Figure S17 for details); calculations for the silica-supported systems were carried out by using $(\mathrm{MeO})_{3} \mathrm{SiO}$ as a simple model to interrogate the electronic effects associated with a surface siloxy ligand. From these data, it appears that the SP metallacycle, recognized as the resting state intermediate of olefin metathesis, is always the lower-energy metallacycle for all calculated complexes. Regarding the TBP intermediates, their free energies are also significantly lower than the energies of the separated reactants for all calculated complexes with the exception of the molecular complexes 2 and 3, where formation of the TBP metallacycle is endergonic by ca. 2 or $3.5 \mathrm{kcal} / \mathrm{mol}$, respectively.

An ideal metathesis catalyst would have a close-to-neutral free energy of formation for the TBP isomer $\left(\Delta G_{\mathrm{TBP}} \approx 0 \mathrm{kcal} /\right.$ $\mathrm{mol}$ ) and a destabilized SP isomer, favoring metathesis over formation of the off-cycle intermediate. The data presented in Table 2 clearly indicate that compound $\mathbf{1}$ allows the formation of not too stable TBP and SP metallacyclobutanes, while 2 and 3 are associated with the positive free energies of formation of the key TBP intermediate, likely associated with a higher barrier for $[2+2]$ cycloaddition. In addition, while not calculated, olefin coordination/cycloaddition in complexes 2 and 3 is likely not favorable because of the bulky aryloxide ligands. In contrast, the silica-supported systems with the significantly smaller and weak $\sigma$-donating surface siloxy ligand $^{13 a, 16}$ are associated with the formation of slightly more stable TBP and SP metallacycles.

This could explain their higher activity with respect to the corresponding molecular complexes 2 and 3. These calculations also highlight the specificity of compound $\mathbf{1}$, containing two very weak $\sigma$-donating $\mathrm{OR}_{\mathrm{F} 9}$ ligands that do not stabilize the metallacycles too much. For $1 @ \mathrm{SiO}_{2}$, two TBP isomers can be formed with the siloxy ligand in either the axial or equatorial position. The free energy of the siloxy equatorial isomer is 2 $\mathrm{kcal} / \mathrm{mol}$ lower compared to the siloxy axial isomer, highlighting the weak $\sigma$-donor ability of $\mathrm{OR}_{\mathrm{F} 9}$ that ends up trans to the very strong $\sigma$-donor oxo ligand. This may explain the lower activity of $1 @ \mathrm{SiO}_{2}$ compared to 1. To better understand the high activity of $\mathbf{1}$, we also evaluated the metathesis pathway. While the olefin complex and associated transition state for coordination could not be located, the $[2+2]$ cycloaddition and turnstile isomerization transition states have very similar and quite low energies: $\Delta G^{\ddagger}{ }_{[2+2]}\left(\Delta H^{\ddagger}{ }_{[2+2]}\right)=8.12(-6.25)$ $\mathrm{kcal} / \mathrm{mol}$ and $\Delta G_{\text {turnstile }}^{\ddagger}\left(\Delta H^{\ddagger}{ }_{\text {turnstile }}\right)=8.38(-6.45) \mathrm{kcal} /$ mol. The combination of facile $[2+2]$ cycloaddition/ cycloreversion and formation of not too stable metallacyclobutanes is consistent with the high catalytic activity of compound $\mathbf{1}$.

\section{CONCLUSIONS}

Overall, this study further illustrates how subtle differences in ligand substitution in Schrock alkylidenes can greatly influence their metathesis activity, pointing out to the need to explore this family of complexes in a more systematic fashion toward the development of detailed structure-activity relationships. This study also illustrates the uniqueness of silica, that enables generated isolated metal sites bound to a weak $\sigma$-donating and rather small siloxy ligand.

\section{ASSOCIATED CONTENT}

\section{(s) Supporting Information}

The Supporting Information is available free of charge at https://pubs.acs.org/doi/10.1021/acs.inorgchem.0c03173.

Details on the reagents used, experimental setups, synthetic procedures, and corresponding characterizations, computational details including atomic coordinates for all calculated structures, experimental procedures for the metathesis tests and corresponding catalytic data, and crystallographic data (PDF)

$x y z$ files for all computed structures (ZIP)

\section{Accession Codes}

CCDC 2053831 contains the supplementary crystallographic data for this paper. These data can be obtained free of charge via www.ccdc.cam.ac.uk/data_request/cif, or by emailing datarequest@ccdc.cam.ac.uk, or by contacting The Cambridge Crystallographic Data Centre, 12 Union Road, Cambridge CB2 1EZ, UK; fax: +44 1223336033.

\section{AUTHOR INFORMATION}

\section{Corresponding Authors}

Christophe Copéret - Department of Chemistry and Applied Biosciences, ETH Zürich (ETHZ), CH-8093 Zürich, Switzerland; ○ orcid.org/0000-0001-9660-3890; Email: ccoperet@ethz.ch

Richard R. Schrock - Department of Chemistry, Massachusetts Institute of Technology, Cambridge, Massachusetts 02139, United States; Email: rrs@mit.edu

\section{Authors}

Jordan De Jesus Silva - Department of Chemistry and Applied Biosciences, ETH Zürich (ETHZ), CH-8093 Zürich, Switzerland

Margherita Pucino - Department of Chemistry and Applied Biosciences, ETH Zürich (ETHZ), CH-8093 Zürich, Switzerland

Feng Zhai - Department of Chemistry, Massachusetts Institute of Technology, Cambridge, Massachusetts 02139, United States; (1) orcid.org/0000-0001-7892-3188

Deni Mance - Department of Chemistry and Applied Biosciences, ETH Zürich (ETHZ), CH-8093 Zürich, Switzerland

Zachariah J. Berkson - Department of Chemistry and Applied Biosciences, ETH Zürich (ETHZ), CH-8093 Zürich, Switzerland

Darryl F. Nater - Department of Chemistry and Applied Biosciences, ETH Zürich (ETHZ), CH-8093 Zürich, Switzerland

Amir H. Hoveyda - Department of Chemistry, Merkert Chemistry Center, Boston College, Chestnut Hill, Massachusetts 02467, United States

Complete contact information is available at: https://pubs.acs.org/10.1021/acs.inorgchem.0c03173

\section{Author Contributions}

${ }^{\dagger}$ These authors contributed equally to this work.

Notes

The authors declare no competing financial interest. 


\section{ACKNOWLEDGMENTS}

J.D.J.S. was supported by the National Research Fund, Luxembourg (AFR Individual Ph.D. Grant 12516655). M.P. is grateful to the Swiss National Science Foundation (SNSF; Grant 200021 169134). D.M. acknowledges support from the ETHZ Postdoctoral Fellowship Program and from the Marie Curie Actions for People COFUND Program. Z.J.B. acknowledges support from a SNSF Spark award (Project CRSK2 190322). D.F.N. was supported by the SNSF (Grant 200020B_192050). R.R.S. and A.H.H. are grateful for financial support from the National Institutes of Health (Grant GM59426). The authors thank Christopher P. Gordon for helpful discussions. We also dedicate this work to Prof. P. H. Dixneuf.

\section{REFERENCES}

(1) (a) Ivin, K. J.; Mol, J. C. Olefin Metathesis and Metathesis Polymerization; Elsevier Science: Oxford, U.K., 2014. (b) Grubbs, R. H. Handbook of Metathesis; Wiley-VCH: Weinheim, Germany, 2014. (c) Malcolmson, S. J.; Meek, S. J.; Sattely, E. S.; Schrock, R. R.; Hoveyda, A. H. Highly efficient molybdenum-based catalysts for enantioselective alkene metathesis. Nature 2008, 456, 933-937. (d) Higman, C. S.; Lummiss, J. A. M.; Fogg, D. E. Olefin Metathesis at the Dawn of Implementation in Pharmaceutical and SpecialtyChemicals Manufacturing. Angew. Chem., Int. Ed. 2016, 55, 35523565. (e) Copéret, C.; Allouche, F.; Chan, K. W.; Conley, M. P.; Delley, M. F.; Fedorov, A.; Moroz, I. B.; Mougel, V.; Pucino, M.; Searles, K.; Yamamoto, K.; Zhizhko, P. A. Bridging the Gap between Industrial and Well-Defined Supported Catalysts. Angew. Chem., Int. Ed. 2018, 57, 6398-6440.

(2) (a) Jean-Louis Hérisson, P.; Chauvin, Y. Catalyse de transformation des oléfines par les complexes du tungstène. II. Télomérisation des oléfines cycliques en présence d'oléfines acycliques. Makromol. Chem. 1971, 141, 161-176. (b) Chauvin, Y. Olefin Metathesis: The Early Days (Nobel Lecture). Angew. Chem., Int. Ed. 2006, 45, 3740-3747.

(3) (a) Poater, A.; Solans-Monfort, X.; Clot, E.; Copéret, C.; Eisenstein, O. Understanding $\mathrm{d}^{0}$-Olefin Metathesis Catalysts: Which Metal, Which Ligands? J. Am. Chem. Soc. 2007, 129, 8207-8216. (b) Buchmeiser, M. R.; Sen, S.; Lienert, C.; Widmann, L.; Schowner, R.; Herz, K.; Hauser, P.; Frey, W.; Wang, D. Molybdenum Imido Alkylidene N-Heterocyclic Carbene Complexes: Structure-Productivity Correlations and Mechanistic Insights. ChemCatChem 2016, 8, 2710-2723. (c) Zhizhko, P. A.; Mougel, V.; De Jesus Silva, J.; Copéret, C. Benchmarked Intrinsic Olefin Metathesis Activity: Mo vs. W. Helv. Chim. Acta 2018, 101, No. e1700302. (d) Ferreira, M. A. B.; De Jesus Silva, J.; Grosslight, S.; Fedorov, A.; Sigman, M. S.; Copéret, C. Noncovalent Interactions Drive the Efficiency of Molybdenum Imido Alkylidene Catalysts for Olefin Metathesis. J. Am. Chem. Soc. 2019, 141, 10788-10800. (e) Pucino, M.; Liao, W.-C.; Chan, K. W.; Lam, E.; Schowner, R.; Zhizhko, P. A.; Buchmeiser, M. R.; Copéret, C. Metal-Surface Interactions and Surface Heterogeneity in 'WellDefined' Silica-Supported Alkene Metathesis Catalysts: Evidences and Consequences. Helv. Chim. Acta 2020, 103, No. e2000072. (f) Schowner, R.; Elser, I.; Benedikter, M.; Momin, M.; Frey, W.; Schneck, T.; Stöhr, L.; Buchmeiser, M. R. Origin and Use of Hydroxyl Group Tolerance in Cationic Molybdenum Imido Alkylidene NHeterocyclic Carbene Catalysts. Angew. Chem., Int. Ed. 2020, 59, 951-958.

(4) (a) Hock, A. S.; Schrock, R. R.; Hoveyda, A. H. Dipyrrolyl precursors to bisalkoxide molybdenum olefin metathesis catalysts. J. Am. Chem. Soc. 2006, 128, 16373-16375. (b) Sinha, A.; Lopez, L. P. H.; Schrock, R. R.; Hock, A. S.; Müller, P. Reactions of M(N-2,6-iPr2C6H3) (CHR) (CH2R')2 ( $\mathrm{M}=\mathrm{Mo}, \mathrm{W})$ Complexes with Alcohols To Give Olefin Metathesis Catalysts of the Type M(N-2,6-iPr2C6H3)(CHR)(CH2R')(OR' '). Organometallics 2006, 25, 1412-1423. (c) Singh, R.; Czekelius, C.; Schrock, R. R.; Müller, P.; Hoveyda, A. H. Molybdenum Imido Alkylidene Metathesis Catalysts
That Contain Electron-Withdrawing Biphenolates or Binaphtholates. Organometallics 2007, 26, 2528-2539. (d) Flook, M. M.; Jiang, A. J.; Schrock, R. R.; Müller, P.; Hoveyda, A. H. Z-Selective Olefin Metathesis Processes Catalyzed by a Molybdenum Hexaisopropylterphenoxide Monopyrrolide Complex. J. Am. Chem. Soc. 2009, 131, 7962-7963. (e) Ibrahem, I.; Yu, M.; Schrock, R. R.; Hoveyda, A. H. Highly Z- and Enantioselective Ring-Opening/Cross-Metathesis Reactions Catalyzed by Stereogenic-at-Mo Adamantylimido Complexes. J. Am. Chem. Soc. 2009, 131, 3844-3845. (f) Jiang, A. J.; Zhao, Y.; Schrock, R. R.; Hoveyda, A. H. Highly Z-Selective Metathesis Homocoupling of Terminal Olefins. J. Am. Chem. Soc. 2009, 131, 16630-16631. (g) Sattely, E. S.; Meek, S. J.; Malcolmson, S. J.; Schrock, R. R.; Hoveyda, A. H. Design and Stereoselective Preparation of a New Class of Chiral Olefin Metathesis Catalysts and Application to Enantioselective Synthesis of Quebrachamine: Catalyst Development Inspired by Natural Product Synthesis. J. Am. Chem. Soc. 2009, 131, 943-953. (h) Reithofer, M. R.; Dobereiner, G. E.; Schrock, R. R.; Muller, P. Monoaryloxide Pyrrolide (MAP) Imido Alkylidene Complexes of Molybdenum and Tungsten That Contain 2,6-Bis(2,5-R2-pyrrolyl)phenoxide ( $\mathrm{R}=\mathrm{i}-\mathrm{Pr}, \mathrm{Ph})$ Ligands and an Unsubstituted Metallacyclobutane on Its Way to Losing Ethylene. Organometallics 2013, 32, 2489-2492. (i) Buchmeiser, M. R.; Sen, S.; Unold, J.; Frey, W. N-Heterocyclic Carbene, High Oxidation State Molybdenum Alkylidene Complexes: Functional-Group-Tolerant Cationic Metathesis Catalysts. Angew. Chem., Int. Ed. 2014, 53, 9384-9388. (j) Sen, S.; Schowner, R.; Imbrich, D. A.; Frey, W.; Hunger, M.; Buchmeiser, M. R. Neutral and Cationic Molybdenum Imido Alkylidene N-Heterocyclic Carbene Complexes: Reactivity in Selected Olefin Metathesis Reactions and Immobilization on Silica. Chem. - Eur. J. 2015, 21, 13778-13787. (k) Elser, I.; Frey, W.; Wurst, K.; Buchmeiser, M. R. Molybdenum Imido Alkylidene Complexes Containing N- and C-Chelating N-Heterocyclic Carbenes. Organometallics 2016, 35, 4106-4111. (1) De Jesus Silva, J.; Mance, D.; Pucino, M.; Benedikter, M. J.; Elser, I.; Buchmeiser, M. R.; Copéret, C. Silica-Supported Cationic Tungsten Imido Alkylidene Stabilized by an N-Heterocyclic Carbene Ligand Boosts Activity and Selectivity in the Metathesis of $\alpha$-Olefins. Helv. Chim. Acta 2020, 103, No. e2000161.

(5) Solans-Monfort, X.; Copeŕet, C.; Eisenstein, O. Oxo vs Imido Alkylidene d0-Metal Species: How and Why Do They Differ in Structure, Activity, and Efficiency in Alkene Metathesis? Organometallics 2012, 31, 6812-6822.

(6) Copéret, C.; Comas-Vives, A.; Conley, M. P.; Estes, D. P.; Fedorov, A.; Mougel, V.; Nagae, H.; Núñez-Zarur, F.; Zhizhko, P. A. Surface Organometallic and Coordination Chemistry toward SingleSite Heterogeneous Catalysts: Strategies, Methods, Structures, and Activities. Chem. Rev. 2016, 116, 323-421.

(7) (a) Mougel, V.; Santiago, C. B.; Zhizhko, P. A.; Bess, E. N.; Varga, J.; Frater, G.; Sigman, M. S.; Copéret, C. Quantitatively Analyzing Metathesis Catalyst Activity and Structural Features in Silica-Supported Tungsten Imido-Alkylidene Complexes. J. Am. Chem. Soc. 2015, 137, 6699-6704. (b) De Jesus Silva, J.; Ferreira, M. A. B.; Fedorov, A.; Sigman, M. S.; Copéret, C. Molecular-level insight in supported olefin metathesis catalysts by combining surface organometallic chemistry, high throughput experimentation, and data analysis. Chem. Sci. 2020, 11, 6717-6723.

(8) (a) Leduc, A. M.; Salameh, A.; Soulivong, D.; Chabanas, M.; Basset, J. M.; Copéret, C.; Solans-Monfort, X.; Clot, E.; Eisenstein, O.; Böhm, V. P. W.; Röper, M. $\beta$-H Transfer from the Metallacyclobutane: A Key Step in the Deactivation and Byproduct Formation for the Well-Defined Silica-Supported Rhenium Alkylidene Alkene Metathesis Catalyst. J. Am. Chem. Soc. 2008, 130, 6288-6297. (b) Solans-Monfort, X.; Copeŕet, C.; Eisenstein, O. Shutting Down Secondary Reaction Pathways: The Essential Role of the Pyrrolyl Ligand in Improving Silica Supported d0-ML4 Alkene Metathesis Catalysts from DFT Calculations. J. Am. Chem. Soc. 2010, 132, 77507757.

(9) (a) Conley, M. P.; Mougel, V.; Peryshkov, D. V.; Forrest, W. P.; Gajan, D.; Lesage, A.; Emsley, L.; Copéret, C.; Schrock, R. R. A Well- 
Defined Silica-Supported Tungsten Oxo Alkylidene Is a Highly Active Alkene Metathesis Catalyst. J. Am. Chem. Soc. 2013, 135, 1906819070. (b) Schowner, R.; Frey, W.; Buchmeiser, M. R. Cationic Tungsten-Oxo-Alkylidene-N-Heterocyclic Carbene Complexes: Highly Active Olefin Metathesis Catalysts. J. Am. Chem. Soc. 2015, $137,6188-6191$.

(10) (a) Mougel, V.; Pucino, M.; Copéret, C. Strongly $\sigma$ Donating Thiophenoxide in Silica-Supported Tungsten Oxo Catalysts for Improved 1-Alkene Metathesis Efficiency. Organometallics 2015, 34, 551-554. (b) Khan, R. K. M.; Torker, S.; Hoveyda, A. H. Readily Accessible and Easily Modifiable Ru-Based Catalysts for Efficient and Z-Selective Ring-Opening Metathesis Polymerization and RingOpening/Cross-Metathesis. J. Am. Chem. Soc. 2013, 135, 1025810261. (c) Mikus, M. S.; Torker, S.; Xu, C.; Li, B.; Hoveyda, A. H. Pentacoordinate Ruthenium(II) Catecholthiolate and Mercaptophenolate Catalysts for Olefin Metathesis: Anionic Ligand Exchange and Ease of Initiation. Organometallics 2016, 35, 3878-3892. (d) Occhipinti, G.; Hansen, F. R.; Törnroos, K. W.; Jensen, V. R. Simple and Highly Z-Selective Ruthenium-Based Olefin Metathesis Catalyst. J. Am. Chem. Soc. 2013, 135, 3331-3334. (e) Smit, W.; Ekeli, J. B.; Occhipinti, G.; Woźniak, B.; Törnroos, K. W.; Jensen, V. R. ZSelective Monothiolate Ruthenium Indenylidene Olefin Metathesis Catalysts. Organometallics 2020, 39, 397-407. (f) Renom-Carrasco, M.; Mania, P.; Sayah, R.; Veyre, L.; Occhipinti, G.; Jensen, V. R.; Thieuleux, C. Silica-supported Z-selective $\mathrm{Ru}$ olefin metathesis catalysts. Molecular Catalysis 2020, 483, 110743. (g) Allouche, F.; Mougel, V.; Copéret, C. Activating Thiolate-Based Imidoalkylidene Tungsten(VI) Metathesis Catalysts by Grafting onto Silica. Asian J. Org. Chem. 2015, 4, 528-532. (h) Tafazolian, H.; VenkatRamani, S.; Tsay, C.; Schrock, R. R.; Müller, P. Syntheses of Molybdenum and Tungsten Imido Alkylidene Complexes that Contain a Bidentate Oxo/Thiolato Ligand. Helv. Chim. Acta 2020, 103, No. e2000068.

(11) (a) Pucino, M.; Mougel, V.; Schowner, R.; Fedorov, A.; Buchmeiser, M. R.; Copéret, C. Cationic Silica-Supported NHeterocyclic Carbene Tungsten Oxo Alkylidene Sites: Highly Active and Stable Catalysts for Olefin Metathesis. Angew. Chem., Int. Ed. 2016, 55, 4300-4302. (b) Imbrich, D. A.; Elser, I.; Frey, W.; Buchmeiser, M. R. First Neutral and Cationic Tungsten Imido Alkylidene N-Heterocyclic Carbene Complexes. ChemCatChem 2017, 9, 2996-3002. (c) Benedikter, M. J.; Ziegler, F.; Groos, J.; Hauser, P. M.; Schowner, R.; Buchmeiser, M. R. Group 6 metal alkylidene and alkylidyne $\mathrm{N}$-heterocyclic carbene complexes for olefin and alkyne metathesis. Coord. Chem. Rev. 2020, 415, 213315.

(12) Zhai, F.; Schrock, R. R.; Hoveyda, A. H.; Müller, P. Syntheses of "Phosphine-Free" Molybdenum Oxo Alkylidene Complexes through Addition of Water to Alkylidyne Complexes. Organometallics 2020, 39, 2486-2492.

(13) (a) Conley, M. P.; Forrest, W. P.; Mougel, V.; Copéret, C.; Schrock, R. R. Bulky Aryloxide Ligand Stabilizes a Heterogeneous Metathesis Catalyst. Angew. Chem., Int. Ed. 2014, 53, 14221-14224.

(b) Pucino, M.; Inoue, M.; Gordon, C. P.; Schowner, R.; Stöhr, L.; Sen, S.; Hegedüs, C.; Robé, E.; Tóth, F.; Buchmeiser, M. R.; Copéret, C. Promoting Terminal Olefin Metathesis with a Supported Cationic Molybdenum Imido Alkylidene N-Heterocyclic Carbene Catalyst. Angew. Chem., Int. Ed. 2018, 57, 14566-14569.

(14) Yamamoto, K.; Gordon, C. P.; Liao, W.-C.; Copéret, C.; Raynaud, C.; Eisenstein, O. Orbital Analysis of Carbon-13 Chemical Shift Tensors Reveals Patterns to Distinguish Fischer and Schrock Carbenes. Angew. Chem., Int. Ed. 2017, 56, 10127-10131.

(15) Pucino, M.; Zhai, F.; Gordon, C. P.; Mance, D.; Hoveyda, A. H.; Schrock, R. R.; Copéret, C. Silica-Supported Molybdenum Oxo Alkylidenes: Bridging the Gap between Internal and Terminal Olefin Metathesis. Angew. Chem., Int. Ed. 2019, 58, 11816-11819.

(16) Solans-Monfort, X.; Filhol, J.-S.; Copéret, C.; Eisenstein, O. Structure, spectroscopic and electronic properties of a well defined silica supported olefin metathesis catalyst, $[(\mathrm{SiO}) \mathrm{Re}(\mathrm{CR})(\mathrm{CHR})-$ $(\mathrm{CH} 2 \mathrm{R})]$, through DFT periodic calculations: silica is just a large siloxy ligand. New J. Chem. 2006, 30, 842-850. 